\title{
A level II reliability approach to tunnel support design
}

\author{
Enrique Laso, M. Sagrario Gómez Lera and Enrique Alarcón \\ Departamento de Mecánica Estructural y Construcciones Industriales, \\ Universidad Politécnica de Madrid, Madrid, Spain
}

\begin{abstract}
A reliability approach to tunnel support design is presented in this paper. The aim of the work is the incorporation of classical Level II techniques to the current design method based on the study of the ground-support interaction diagram.
\end{abstract}

Keywords: reliability, tunnel design, safety margins, point estimate method, limit state design

\section{Introduction}

Tunnelling has become a key task in the development of both the mining industry and road or railway communications. Because of its intrinsic complexity and the high number of factors involved, this type of projects has traditionally been considered work of high and undefined risk.

The diffusion of the New Austrian Tunnelling Method (NATM; Refs. 1-3) meant a notable impulse for technical advancement in this engineering field. However, paradoxically, the problem of safety level assessment is even now reduced to the calculation of a unique margin of safety the definition of which does not fulfill current requirements.

The purpose of the work described in this paper ${ }^{4-6}$ has been the introduction of modern techniques of structural reliability in the design model for tunnel support structures proposed by the NATM. With this objective, the characteristic curves method (interaction diagram) has been used to approach the mechanical problem. Point 2 of the paper is devoted to briefly describing the corresponding formulation. The third section includes an introduction to structural reliability and a summary of the basic Level II techniques applied to develop this work. Point 4 then describes the proposed reliability model itself: the limit states definition, random variables selection, and methodology employed. Eventually, the last section includes some results obtained from the application of the model to practical design situations. Some guidelines are proposed to calibrate partial safety factors to be included in a standard load and resistance factors design-type format.

Address reprint requests to Dr. Enrique Alarcón, Departamento de Mecanica Estructural y Construcciones Industriales, Universidad Politecnica de Madrid, Madrid, Spain.

Received 6 March 1994; revised 25 November 1994; accepted 16 January 1995

\section{Mechanical model: Ground-structure interaction}

Usually, to design the structure of a tunnel support, preliminar calculations are based on the characteristic curves method. The ground characteristic curve represents graphically the analytical relationship existing between the radial interaction pressure $\left(P_{i}\right)$ applied in a point of the excavation boundary and the radial displacement $\left(U_{\mathrm{r}}\right)$ experimented by this point (Figure l). Similarly, the support characteristic curve relates the radial pressure due to ground thrust $\left(P_{i}\right)$ and the radial displacement measured in the corresponding point of support structure (Figure 2).

The equilibrium situation in the problem is determined by a displacement compatibility condition.

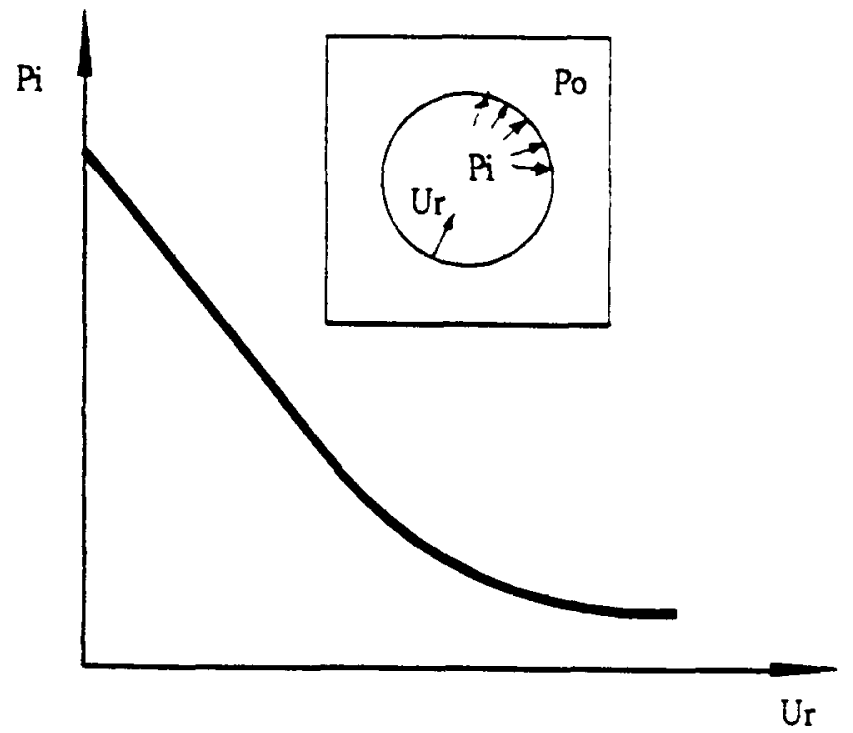

Figure 1. General appearance of ground elastoplastic characteristic curve 


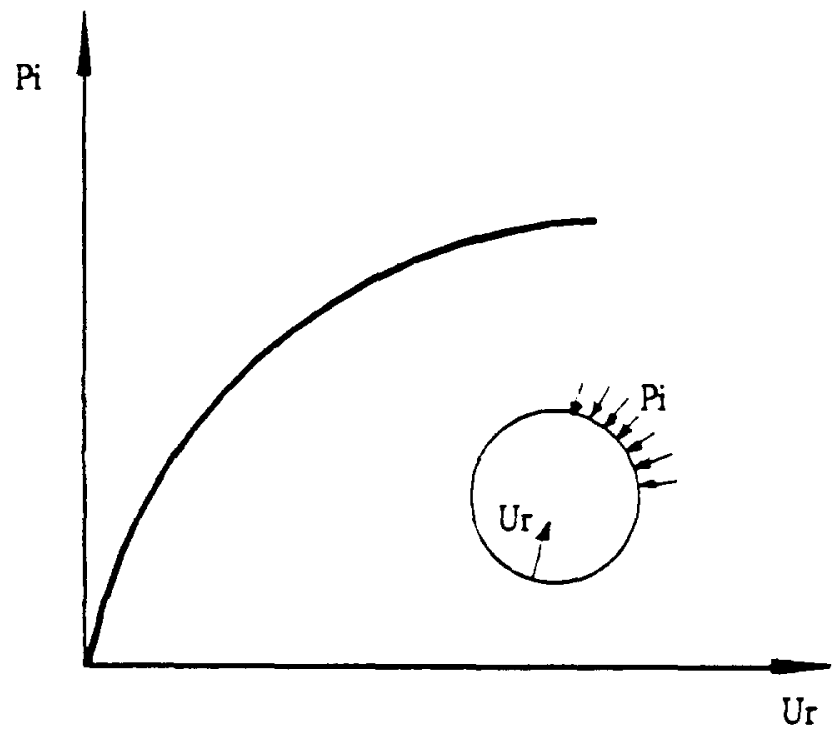

Figure 2. General appearance of support structure nonlinear characteristic curve

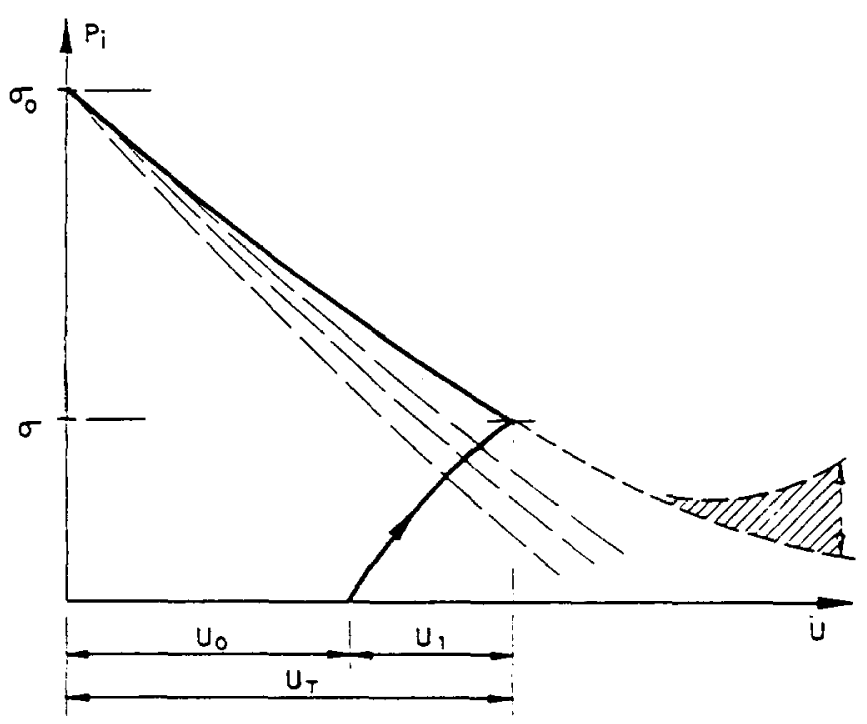

Figure 3. Ground-support structure interaction diagram

That is, graphically it corresponds to the point defined by the intersection of ground and support characteristic curves. Additionally, to obtain this point, it is necessary to consider the lag in displacements defined between both curves $\left(U_{0}\right)$. The lag is due to the delay existing since the excavation moment until that when the support structure is effective (ground-support interaction diagram, Figure 3).

Traditionally, the safety factor has been defined as the quotient between the maximum pressure that the structure is able to bear (ultimate pressure) and the interaction pressure reached at the equilibrium situation. Though there are important three-dimensional (3D) effects due to the proper drilling process and the ground delayed readaptation, ${ }^{7,8}$ the formulation of characteristic curves is usually carried out for a plane strain condition.
Different models have been developed in this line. The degree of complexity depends on the magnitude of the simplifying hypothesis assumed in each case.

\subsection{Ground characteristic curve formulation}

In this work, the formulation of a ground characteristic curve has been partially based on the $2 \mathrm{D}$ plane strain analytical model proposed by Fritz. ${ }^{9}$ This model can be considered a generalization of that proposed by Rabcewicz, ${ }^{3}$ the major NATM diffuser. Fritz considers the case of circular excavations when the medium is subjected to a load condition defined by axisymmetric internal and far-field pressures. Starting from a nonassociative elastoplastic model, the idea of time dependence in ground response is introduced to finally obtain a viscoelastoplastic analytical solution. Time dependence is modelled by means of a modified St. Venant slider.

For simplicity, the generalization mentioned earlier has not been included in the work presented in this paper, and thus soil time-dependent properties are not considered. Hence, the analytical model used to develop the soil characteristic curve in this work presents the following major assumptions:

- Plane strain and axial symmetry.

- Circular shape excavation.

- Homogeneity and isotropy of ground medium

- Far-field pressures are supposed to be uniform.

- The material is assumed to be elastoplastic. MohrCoulomb yield conditions are considered and dilatant plastic deformations are accepted according to a nonassociative flow-rule.

- Strain softening is also introduced so that both peak and residual soil strengths are taken into account.

Appendix 1 of this paper presents the basic formulation resulting from a soil model with these characteristics.

\subsection{Formulation of the characteristic curve of the liner}

The NATM proposes the use of flexible liners. In those structures, several elements are combined in a tailored way according to soil characteristics. The aim is to gain a suitable stiffness level in order to reach the optimum equilibrium situation. Later on, a second concrete ring is very often disposed. However, the function of that second liner is not strictly structural. ${ }^{10}$ The most important elements usually included in the support structure are the following: shotcrete, steel reinforcement, steel frames, and bolts, either tensioned-anchored bolts or untensioned grouted bolts.

In many models used for practical purposes (e.g., in Spain ${ }^{11}$ ), the liner is roughly defined as a perfect elastoplastic body. Following this approach, support response is linear elastic for pressure levels under plastification conditions. From this point on, the pressure remains constant for growing displacements up to that corresponding with the ultimate strain. Support 
stiffness in such a model is computed in a simplified way from those furnished by the different elements.

In this work, a slightly more refined approach has been followed. The idea of a circular ring is adopted, but to formulate the liner characteristic curve, the standard stress-strain diagrams for both concrete and steel have been taken into account. Additionally, the contribution of bolts has been computed in a similar way to that proposed by Hoek and Brown. ${ }^{12}$ Other authors ${ }^{13}$ have proposed including the effect of grouted bolts in the formation of the soil characteristic curve instead of in the support one. This point is based on the idea that grouted bolts do not directly affect support stiffness, but they do modify the medium surrounding the excavation, producing a confinement effect that induces an increase of ground mechanical properties. That approach has not been followed in this work. As a result, the liner characteristic curve considered in this work is not linear although it is composed by a user-defined number of linear segments. Appendix 2 summarizes the formulation applied to compute that curve.

\section{Level II structural reliability methods}

Until fairly recently, structural design has relied on deterministic analysis. However, it is now widely recognized that in assessing structural safety, different sources of uncertainty are relevant. Therefore, almost every design parameters should be regarded as a random variable even in the case that the design model itself is considered deterministic. As a result, it is recognized also that absolute safety is unattainable so that some risk of unacceptable structural performance must be tolerated. Thus, the object of structural design becomes to ensure, at an acceptable level of probability, that structures will not become unfit for their intended purpose during their design life.

Structural reliability theory is concerned with the methods for assessing the safety and serviceability of structures by means of a rational statistical treatment of the uncertainties involved in structural engineering. Most structures have multiple performance requirements, that are commonly expressed by a set of ultimate and serviceability limit states. In the mathematical formulation, the limit states are described in terms of failure functions, $g\left(x_{i}\right)$, that represent surfaces subjected to statistical variation in the space of random variables of the problem:

$$
g\left(x_{i}\right) \begin{cases}>0 & \text { safe set } \\ =0 & \text { limit state surface } \\ \leq 0 & \text { safe set }\end{cases}
$$

The probability of failure is given by

$$
P_{\mathrm{f}}=\int_{g\left(x_{i}\right) \leq 0} f\left(x_{i}\right) d v
$$

where $f\left(x_{i}\right)$ represents the joint probability density function of the set of variables $x_{i}$.

When the state of knowledge in a reliability problem is perfect, a strict measure of structural safety is the probability of failure, $P_{\mathrm{f}}$. However, when the state of knowledge is imperfect (incomplete statistical information or model imperfection) $P_{\mathrm{f}}$ is itself uncertain so that a strict assessment of structural safety is not feasible. In many cases, the available statistical information only includes the first two moments (mean value, standard deviation, and correlation coefficients) of all the variables included in the model. Reliability methods using only this information are called Level II or second moment reliability methods. ${ }^{14}$

\subsection{Reliability index}

The common unit to quantify structural reliability is the reliability index usually denoted by $\beta$. Within second moment theory, the first formal definition of such a magnitude was introduced by Cornell ${ }^{15}$ as the ratio of the mean value to the standard deviation of the limit state function $g\left(x_{i}\right)$ :

$$
\beta=\frac{\mu_{g}}{\sigma_{g}}
$$

in the special case when all the variables are normal and $g\left(x_{i}\right)$ is linear (complete statistical information) then:

$$
P_{\mathrm{f}}=1-\Phi(\beta)
$$

where $\Phi$ represents the standard normal distribution function.

However, in general $g\left(x_{i}\right)$ is nonlinear. Thus, though all the variables are inherently normally distributed, $g\left(x_{i}\right)$ is not. Therefore, it is necessary to linearize the limit state function to compute $\mu_{g}$ and $\sigma_{g}$. This is usually carried out by means of first-order Taylor series expansion. Approximations based on the linearization of the limit state function are denoted as first order methods.

A problem with Cornell's definition of $\beta$ that was soon realized $^{16,17}$ is that it is not invariant with respect to the formulation of the limit state function. This problem was solved by Hasofer and Lind who proposed expanding the Taylor series around a point $y_{i}^{*}$ of the limit state surface (checking or design point) with minimum distance from the origin in a transformed standard space:

$$
Y_{i}=\frac{x_{i}-\mu_{x_{i}}}{\sigma_{x_{i}}} ; Y_{i} \sim N(0,1)
$$

$\beta$ (first order second moment [FOSM], reliability index) is then defined as the mentioned minimum distance, and the design point represents the point of maximum likelihood. For linear limit state functions both definitions of $\beta$ are coincident.

The transformation in equation (5) can be easily performed if the variables $x_{i}$ are uncorrelated. If not, an intermediate step is required to obtain a set of independent variables $x_{i}^{\prime}$ from the initial ones. At Level II, the procedure, an orthogonal transformation of normal variables, consists basically in an eigenvalue analysis. $^{18}$

Additionally, in the case that some variables follow other non-normal types of known probability distributions, it is possible to incorporate this extra information 
by transforming them locally to equivalent normal variables (normal tail transformation). ${ }^{19}$ This procedure is sometimes called the extended FOSM method. More recently, many other definitions of the reliability index have been proposed. Some of them are intended to obtain a consistent definition of $\beta$ as a statistical measure and refer to general imperfect states of knowledge including also model and estimation uncertainties. ${ }^{20,21}$ They are beyond the scope of the present work.

\subsection{Point estimate method}

Within Level II, the application of FOSM methods requires the evaluation of derivatives. Sometimes this is not easy (for instance when the failure functions are not explicit or are highly nonlinear expressions) or even not a feasible task (e.g., those cases when the solution to the mechanical problem is obtained by means of numerical methods). Such a problem can be circumvented by the use of the point estimate method (PEM) proposed by Rosenblueth. ${ }^{22}$ The PEM is an approximate method that allows estimating the first two moments of a function $y=f\left(x_{i}\right)$ (the limit state function in this case) of random variables of which the first two moments are known (Level II information). Once the estimation of the mean value and standard deviation of the limit state function is accomplished, if the hypothesis of normality is adopted, the evaluation of the reliability index can be performed through Cornell's definition.

For functions of a single random variable, the method requires two concentrations (two points for which the value of the function is computed) to replace the probability density function of the variable. If the function depends on two or more variables, a larger number of concentrations is necessary. In the case of Level II defined variables (inherently normally distributed), two concentrations per variable are required. Thus, the method is based in the repetitive calculation of the value of the limit state function for a set of $2^{n}$ predefined combinations of the $n$ random variables:

$$
\stackrel{G_{( \pm \pm \ldots . \pm \pm ⿱ 亠}}{=} \stackrel{\underline{G}}{ }\left[\overline{\bar{x}}_{1} \pm \sigma\left(x_{1}\right), \bar{x}_{2} \pm \sigma\left(x_{2}\right), \ldots, \bar{x}_{n} \pm \sigma\left(x_{n}\right)\right]
$$

Expressions are provided to approximate the values of the first two moments of the limit state function:

$$
\begin{aligned}
E[G]= & p_{+}+\ldots+\cdot G_{++\ldots+}+p_{++\ldots-} \cdot G_{++\ldots-} \\
& +\cdots+p_{--\ldots-} \cdot G_{--\ldots-} \\
E\left[G^{2}\right]= & p_{+}+\ldots+\cdot G^{2+\ldots+}+p_{++\ldots-} \cdot G^{2+\ldots-} \\
& +\cdots+p_{--\ldots-} \cdot G^{2-\ldots-}
\end{aligned}
$$

In those expressions, the correlation coefficients between the variables $\rho_{i j}$ are taken into account within the weighting parameters $p$ :

$$
p_{ \pm \pm \ldots \pm}=\frac{1}{2^{n}}\left[1+\sum_{i, j}\left( \pm \rho_{i j}\right)\right]
$$

where the sign applied to $\rho_{i j}$ is positive when in the specific iteration both variables $i j$ are either incremented or decremented in relation to their mean values and negative if one variable is incremented and the other is decremented.

The idea behind the method this way summarized ${ }^{23}$ is that the weighting parameters $p$ adjust the information concerning the independent variables on the basis of the correlation between them. Then the information about the distribution of those variables is transferred through the functional relationship $y=f\left(x_{i}\right)$ (Figure 4). Finally the first two moments of the joint probability distribution function are generated using equations (7) and (8).

\subsection{Response surface method}

As mentioned in the previous point, in practice it is seldom feasible to define an analytical description of a mechanical system. Therefore, the analysis of the system can only be done by means of numerical algorithms (i.e., FEM or BEM analysis). Then the problem is to describe the randomness of a system's response as a result of the randomness of the design variables. Two basic aspects are of interest ${ }^{24}$ : to measure the overall uncertainty of the output variable, to which the most direct approach are the Monte Carlo simulation techniques; and to measure the influence of each variable in the global response of the system, which constitutes the basis of the stochastic finite element techniques and among them the response surface method (RSM). ${ }^{24-27}$ The RSM uses a polynomial expansion (the response surface) to describe the dependency of the output variable on the independent variables:

$$
y=F\left(x_{i}, \delta_{j}\right)+\varepsilon
$$

where $F$ is a first- or second-order polynomial expression, $\delta_{j}$ is a set of unknown parameters to be calculated, and $\varepsilon$ is a random term contributed by the

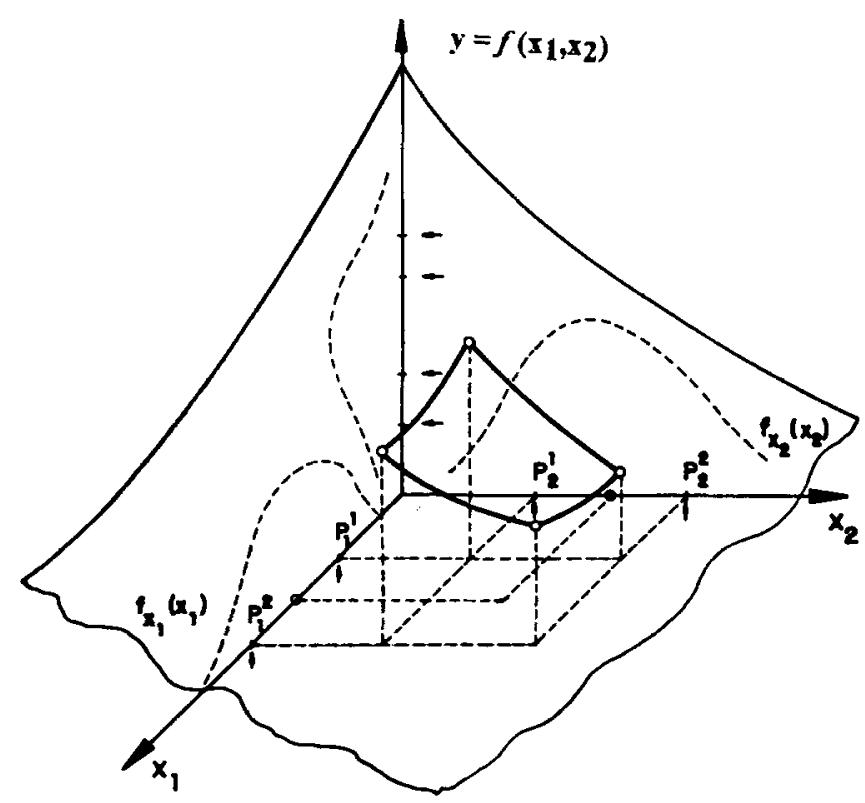

Figure 4. PEM: schematic representation of transfer of information for functions of two random variables (after Harr ${ }^{23}$ ) 
neglected higher terms ("lack of fit") and by intrinsic randomness ("pure error").

In order to determine the value of the elements in $\delta$, an appropriate experimental plan must be defined. ${ }^{28,29}$ Each numerical experiment consists of the calculation of system's response for a predefined specific value of the design variables. The number of experiments to be performed should be high enough to allow the evaluation of the elements in $\delta_{j}$ by means, for instance, of a least squares fit. Finally the variance of the error term $\varepsilon$ and the influence of each design variable are computed through a multiway analysis of variance (ANOVA) of the experimental data. ${ }^{30.31}$ This completes the definition of the model, which can be validated through statistical testing ( $\mathrm{F}$ tests, analysis of residues, etc).

\subsection{Design code calibration}

FOSM reliability methods have been intensively applied in the development of modern structural design codes. ${ }^{32.33}$ In such codes, partial factors for load and resistance variables are included in the so-called load and resistance factors design formats (LRFD). Those factors are computed as a result of a target reliability index which is set in accordance to accepted practice. Thus, $\beta$ is used as a relative measure of safety for comparison.

The starting point is an LRFD format:

$$
\phi R \geq \sum_{i=1}^{n} \gamma_{i} S_{i}
$$

where $\gamma_{i}$ represents the partial factor applied to load variable $S_{i}$, and $\phi$ stands for the minoration factor applied to the generic resistance of the structural system. Then it is possible to develop expressions that relate the value of $\gamma_{i}$ and $\phi$ with a prefixed target value of $\beta$ :

$$
\begin{gathered}
\gamma_{i}=\frac{X_{i}^{*}}{\mu_{i}}=1-\frac{\sigma_{i}}{\mu_{i}} \beta \alpha_{i}^{*} \\
\Phi=\frac{X_{R}^{*}}{\mu_{R}}=1-\frac{\sigma_{R}}{\mu_{R}} \beta \alpha_{R}^{*}
\end{gathered}
$$

where $X_{i}^{*}$ is the checking point value of variable $i$, $\mu_{i}$ and $\sigma_{i}$ its mean value and standard deviation, and finally, $\alpha_{i}^{*}$ represents the sensitivity coefficient of variable $i$ evaluated at the checking point and defined as

$$
\begin{aligned}
\alpha_{i}^{*} & =\left.\frac{\partial \beta}{\partial Z_{i}}\right|_{Z^{*}} \\
Z^{*} & =\text { checking point } \\
Z_{i} & =\frac{x_{i}-\mu_{i}}{\sigma_{i}}
\end{aligned}
$$

\section{Proposed structural reliability model}

This section presents the master lines of the reliability scheme proposed to study the geomechanical problem described in point 2 .

\subsection{Limit states considered in the model}

Among the different limit states that have been defined for tunnel design, ${ }^{34}$ three basic ones have been selected to accomplish this work.

1. Ultimate limit state of soil bearing capacity. Since the soil surrounding the excavation plays an important role in tunnel stability, this limit condition is intended to evaluate the potential risk of collapse due to ground disgregation. This state is analyzed at a complete ground-support section level. The range of plastified material surrounding tunnel contour (plastification radius) is computed at an equilibrium situation. Hence, the ground is considered at ultimate condition when the quotient, $\alpha$, between that radius, $\rho$, and excavation radius, $R$, takes a limit value, $\alpha^{*}$, usually near 2 , empirically defined for each soil type.

When the equilibrium is obtained within elastic range, the solicitation level is quantified by the value of the over-stress ratio (OSR) factor $(0 \leq \mathrm{OSR} \leq 1)$ computed at excavation contour. As it is known, the OSR is defined as the rate between an elastic stress state and that homothetic one corresponding to the plastic condition. For 2D cases, assuming Mohr-Coulomb criteria, an analytical expression for OSR can be obtained in the form

$$
\operatorname{OSR}=\frac{P_{0}-P_{\mathrm{i}}}{P_{0} \sin \varphi+c \cos \varphi}
$$

where $P_{0}$ and $P_{i}$ stand for far-field and interaction pressures. and $c$ and $\varphi$ are ground cohesion and internal friction angle. As a result, a simplified limit state function and failure criteria can be established as follows:

$$
F F_{1}=\alpha^{*}-\alpha \leq 0
$$

$\alpha$, called the plasticity factor, is defined as the quotient $\rho / R$ except in the case of ground elastic equilibrium when $\alpha$ is computed as the OSR value at excavation contour.

2. Ultimate limit state of support bearing capacity. This ultimate limit state is studied at a structural element section level. The limit condition arises when the strain levels reach an ultimate value $\varepsilon^{*}$ corresponding to support structure rupture. Due to the structural model employed, $\varepsilon^{*}$ coincides with the ultimate strain of concrete subjected to simple compression. According to concrete codes, $\varepsilon^{*}=0.0020$ can be considered a standard value. In each case, it is necessary to determine the ground-support equilibrium point as the intersection of both characteristic curves. Once that point is known, the value of this second limit state function is obtained as

$$
F F_{2}=\varepsilon^{*}-\frac{U_{\mathrm{s}}}{R}=\varepsilon^{*}-\frac{U_{\mathrm{t}}-U_{0}}{R}
$$

where $U_{\mathrm{s}}$ is the radial displacement of the structure, $R$ is its radius, $U_{\mathrm{t}}$ is the radial displacement of the excavated soil boundary at equilibrium condition, and 
$U_{0}$ stands for previous ground displacement (Figure 3).

3. Serviceability limit state of excessive structural displacement. Since the support is modelled as a ring, it is supposed to work subjected to simple compression only. As a result, the stiffness of such a structural model is very high. Nevertheless, it is possible to think that the purpose of a specific project could impose very restrictive conditions on allowable structural strain levels. This limit state is intended to consider such a situation. Since safety is not necessarily compromised, it is considered a serviceability limit state. This limit condition affects structural strain so that when the excavation is self-stabilized it is not considered.

As in the previous limit states, the first step consists of the determination of the ground-support equilibrium point. Once this point is known, the value of the limit state function is computed directly as the difference with the fixed limit value

$$
F F_{3}=U^{*}-U_{\text {s }}
$$

As is usual, in all cases positive values of a limit state function reflect safe situation of the system in relation to the corresponding limit state, while negative values correspond to conditions of limit state violation.

\subsection{Basic random variables}

For the purpose of quantifying uncertainties, in this reliability scheme the following magnitudes have been considered as basic random variables:

In relation to the soil:

- Young's modulus, $E_{\mathrm{t}}$

- Poisson's modulus, $v_{\mathrm{t}}$

- Internal friction angle, $\phi_{\mathrm{t}}$

- Cohesion, $C_{\mathrm{t}}$

- Excavation depth, $H$

- Density, $\gamma_{t}$

To define support structure:

- Ground displacement previous to support actuation, $U_{0}$

- Shotcrete average resistance, $F_{\mathrm{c}}$

- Shotcrete layer thickness, $t$

- Tunnel radius, $R$

- Geometric density of steel reinforcement, $\omega_{\mathrm{s}}$

- Steel equivalent section aported by frames (section + distance), $\omega_{\mathrm{c}}$

- Bolt length, $L_{\mathrm{b}}$

- Bolt geometric density, $D_{\mathrm{b}}$

- Bolt diameter, $\Phi_{\mathrm{b}}$

Not always will all the variables included in the foregoing set be considered random ones. Actually, it is possible to neglect the variability of one or more of those variables through the assignation of null variation coefficients.

Apart from the basic random variables, the model includes additional quantities the variability of which have been considered neglectable in comparison with those of the basic variables. Because of this, for the analysis their value has been set in a deterministic way. Among these parameters it is possible to mention the Young's modulus of steel; the yield stress for steel in reinforcement, frames, and bolts; the ultimate strain of concrete under simple compression, etc.

\subsection{Reliability methods applied in the analysis}

The soil-structure interaction problem studied in this work presents several difficulties that reduce the applicability of FOSM techniques used to compute the reliability index:

- The intrinsic complexity of the mechanical model and its marked nonlinear character;

- The high number of variables involved in the problem and the high uncertainty and variability ranges of some of them; and

- The fact that it is not possible to obtain, from the basic variables, explicit analytical formulations for the three selected limit state functions. Therefore, it is necessary to make use of either implicit function or numerical derivation procedures to support FOSM techniques.

Anyway, a complete FOSM scheme has been developed. However, the implementation in a computer program has revealed the existence of numerical problems that affect the stability of the algorithm.

Alternatively, to develop a procedure with a wide applicability range, both the PEM and the RSM have been used. In the first case, the method allows obtaining an estimation of the mean value and the standard deviation of the random variables representing the value of the three limit state functions. Knowing only those two parameters of each limit state function, the principle of maximum entropy suggests the use of the normal distribution. Hence, the corresponding reliability indexes can be evaluated by application of Cornell's definition (3), and the respective nominal failure probabilities are computed as:

$$
P f_{i}=\Phi\left[-\beta_{i}\right]
$$

where $\Phi$ represents the distribution function of an standard normal variable $(\mu=0, \sigma=1)$. Such a PEMbased procedure has been implemented in a personal computer program.

Additionally, a simplified RSM procedure has been developed to obtain an estimation of the value of sensitivity factors corresponding to each basic variable for each limit state function. In this case, use has been made of the population of values of the limit state functions generated by PEM application $\left(2^{n}\right.$ values of each function, $n=$ the number of random variables). From these populations, linear expressions for the corresponding failure surfaces in the transformed space (5) are interpolated by means of a minimum squares procedure:

$$
W_{i}=a_{0}+\sum_{i=1}^{n} a_{i} X_{i}
$$


Once the failure surfaces are approximated, it is possible to compute the value of the sensitivity factors as well, and the position of the design point by application of the Hasofer-Lind definition of reliability index:

$$
\begin{aligned}
& \beta \propto L=\frac{a_{0}}{\sqrt{\sum_{i=1}^{n} a_{i}^{2}}} \\
& \alpha_{i}=\frac{a_{i}}{\sqrt{\sum_{i=1}^{n} a_{i}^{2}}} \\
& \mathrm{X}_{i}^{*}=L \alpha_{i}=\frac{a_{0} a_{i}}{\sum_{i=1}^{n} a_{i}^{2}}
\end{aligned}
$$

In practice, the values of $\beta$ calculated in that way have shown a good correlation with those obtained through the application of PEM.

Finally, as mentioned in point 3.3 , from the values computed for the sensitivity factors it is possible to calibrate partial safety factors to be included in a LRFD-type design format. Since those values, in this case, are only an estimation, the calibration procedure should be applied with some precautions, also taking into account the results obtained from parametric studies.

\section{Results}

This point presents some results that have been obtained from the application of the proposed reliability model to different real design situations. Initially, two tunnel sections are analyzed to determine reliability indexes. The following conclusions relative to parametric studies and partial safety factor calibration are presented. The data to develop the analysis has been obtained from $\mathrm{El}$ Padrún tunnels recently built in the North of Spain. ${ }^{35}$

\subsection{Examples}

Two practical situations are presented herein. In both cases the same data have been considered to set up limit state critical conditions:

- Limit state of soil bearing capacity; the critical condition is considered fulfilled when the plasticity factor $\alpha$ takes a value of $2\left(\alpha^{*}=2\right)$.

- Limit state of support bearing capacity; the critical condition is set for a maximum strain $\varepsilon^{*}=0.0020$.

- Limit state of excessive structural displacement: $U^{*}=3 \mathrm{~cm}$ is considered the maximum allowable radial displacement of the structure.

\section{Example 1}

It reproduces a common practical situation. Figure 5

\begin{tabular}{|c|c|c|c|}
\hline DESIGN VARIABLE & Mean Value & Var. Coef. & Stand Dev. \\
\hline Ground Young modtus & $4 \longdiv { 3 \mathrm { UE } + 0 9 }$ & $30 \%$ & $1.29+09$ \\
\hline Ground Poisson modutus & 1,90E-OT & $10 \%$ & $1,90 E-02$ \\
\hline Ground density & $2,30 E+04$ & $5 \%$ & $1,15 \mathrm{E}+03$ \\
\hline Excavalion depth & $2,00 E+02$ & $10 \%$ & $2,00 E+01$ \\
\hline Giound cohesion & $1,78 E+05$ & $40 \%$ & $7.12 \mathrm{E}+04$ \\
\hline Ground internal friction angle & $2,25 \mathrm{E}+01$ & $17 \%$ & $3835+00$ \\
\hline Pievous gound displacement & $1,50 \mathrm{E}-02$ & $40 \%$ & 6.00E-03 \\
\hline Sholcrete resistance & $3,11 E+07$ & $15 \%$ & $4,67 \mathrm{E}+0 \overline{6}$ \\
\hline Sholcrele layer thickness & $250 E-01$ & $25 \%$ & $6.25 \mathrm{E} \cdot 02$ \\
\hline Excavalion ladius & $5,50 E+00$ & $5 \%$ & $2,75 \mathrm{E} \cdot 01$ \\
\hline Geom dens. leinforcement steel & $1,50 E \cdot 03$ & $1 \%$ & $1,50 \mathrm{E}-05$ \\
\hline Geom dens. sleel frames & $1,38 E-02$ & $20 \%$ & $2,7 \bar{E} \cdot 03$ \\
\hline Bolts length & $400 E+00$ & $10 \%$ & $4,0 \mathrm{XE} \cdot 01$ \\
\hline Bols geometric derisity & $1,0 \mathrm{OE}+00$ & $30 \%$ & $3,00 \mathrm{E} \cdot 01$ \\
\hline Bolts diameler & $2,50 \mathrm{C}-02$ & $5 \%$ & $1,255-03$ \\
\hline
\end{tabular}
presents the problem and includes the interaction

\begin{tabular}{|c|c|c|c|c|}
\hline LIMIT STATE & Mean Val. & Stand Dey. & Rel. Index & Prob. falure \\
\hline 1 Glound exhaustion & $2,22 \mathrm{E}-\mathrm{O}$ & $1,70 \mathrm{E}-01$ & 1,3 & $9,5500 \%$ \\
\hline 2 Support exhaustion & $9,87 \mathrm{E} \cdot \mathrm{Q4}$ & $7,42 \mathrm{E}-\mathrm{M4}$ & 1,33 & $9,1810 \%$ \\
\hline 3 Excest. Alruct suain & 2,44E-0 & 4,16E.03 & 5.87 & $<1,00 \mathrm{E} .5 \%$ \\
\hline
\end{tabular}
diagram where the characteristic curves are plotted for

\section{EXAMPLE 1: AVERAGE VALUE}

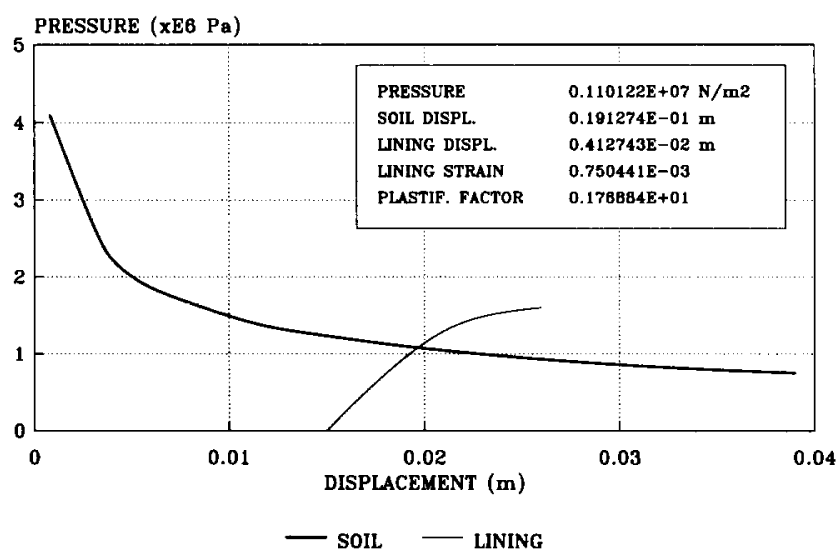

Figure 5. Results Example 1, basic data (S.I. units), reliability results, and mean values interaction diagram

the mean values of the variables. If a deterministic safety factor is evaluated for the same mean value condition, a value near to 1.5 is obtained. Nevertheless, the results from reliability analysis are much more conservative and bring values around 1.3 for the first and second limit states reliability indexes (nominal failure probabilities near $10 \%$ ).

\section{Example 2}

In this case (Figure 6) a special situation has been selected. It corresponds to a self-stabilized excavation (no support structure is strictly needed if the mean values of the variables are considered). When the reliability analysis is carried out, the effects of random variables scattering is manifested:

- For the first limit state, the reliability index only reaches a value of $0.82 \quad(20 \%$ nominal failure probability). 
- For the second limit state, even though according to the mean values the structure would not work, it becomes clear that it is not the same for diverse situations derived from the random character of the

\begin{tabular}{|c|c|c|c|}
\hline DESIGN VARIABLE & Mean Value & Var. Coef. & Stand Dey \\
\hline Ground Young modulus & $2,00 E+10$ & $35 \%$ & $7,0 \mathrm{E}+0 \mathrm{DB}$ \\
\hline Ground Porsson modulus & 2,EOE.07 & $10 \%$ & $2,600-02$ \\
\hline Ground density & $2,40 E+04$ & $5 \%$ & $1,20 E+03$ \\
\hline Excavation depth & $2,00 E+02$ & $10 \%$ & $2,00 E+01$ \\
\hline Ground cohesion & $3,50 E+105$ & $40 \%$ & $1,40 E+05$ \\
\hline Ground internal fiction onge & $3,50+01$ & $17 \%$ & $5,9 x+\infty$ \\
\hline Pievious ground displacement & $1,50 E \cdot 02$ & $40 \%$ & 6,00E-03 \\
\hline Sholctele resistance & $3,11 \mathrm{E}+07$ & $15 \%$ & $4,6 \pi+06$ \\
\hline Sholcrete byet thickness & $5,000 \cdot 02$ & $25 \%$ & $1,25 \mathrm{E}-02$ \\
\hline Excavation ladius & $5,50 \mathrm{E}+00$ & $5 \%$ & $2,75 E-01$ \\
\hline Geom dens reiforcement sted & $3,605-03$ & $1 \%$ & $3,60 \mathrm{CO}$ \\
\hline Bolk lenghth & $4,00 E+100$ & $1 \%$ & $4,00 E-02$ \\
\hline Bolls geometic density & 5,00E-01 & $30 \%$ & $1.5 \mathrm{DE} \cdot 01$ \\
\hline Golis diander & $2,50 E-02$ & $5 \%$ & $1,25 \pm \cdot 03$ \\
\hline
\end{tabular}

\begin{tabular}{|c|c|c|c|c|}
\hline LIMIT STATE & Mean Val & Stand Der & Rel Index & Prob. Failure \\
\hline 1 Ground extraustion & 2,63E-01 & $3,18 E-07$ & 0,83 & $20,4300 \%$ \\
\hline 25 tppot exhausion & $1,5 \mathrm{EE} \cdot 03$ & $6,2 \overline{7 k} \cdot 04$ & 2,53 & $0,5785 \%$ \\
\hline उExcess. sinuct strán & $3.15 E \cdot 02$ & $7,77 E-03$ & 4,06 & 0,00256 \\
\hline
\end{tabular}

\section{EXAMPLE 2: AVERAGE VALUE}

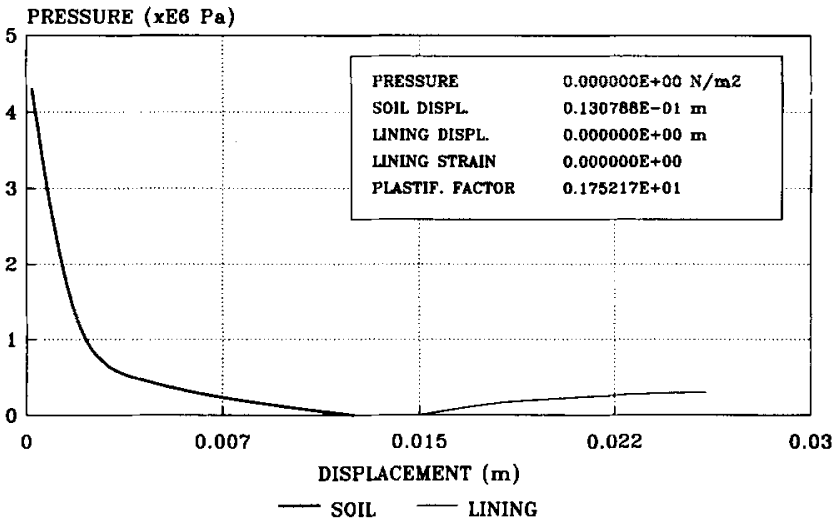

Figure 6. Results Example 2, basic data (S.I. units), reliability results, and mean values interaction diagram basic variables. Hence, the reliability index results 2.5 ( $0.6 \%$ nominal failure probability).

In both cases the set of basic random variables has been supposedly correlated. Thus, it has been necessary to make an estimate of the values included in the correlation matrix considered in the analysis. That matrix is presented in Table 1.

\subsection{Parametric studies and partial safety factors calibration}

Some parametric studies have been conducted to analyse the relative influence of the different random variables in the general response of the reliability model. Those studies are reported in Refs. 4 and 6 . As a result, it is possible to classify the variables into resistance, when a positive increase of the variable induces a positive increase of the reliability index, or load when the effect is the opposite. Moreover, the influence of one variable scattering can be measured. Table 2 includes some results in this line: it shows how the results included in Example 1 are modified, in terms of increments of the reliability indexes with respect to those reported in point 5.1 , when the coefficient of variation of different variables is modified between $10-80 \%$.

The information obtained from parametric studies is also applied to support the calibration of partial safety factors, to be included in a proposal of a design format. The basic values of these factors are obtained from the calculation procedure described in point 4.3 . The final results of the process involved are curves like those presented in Figures 6 and 7. They represent, for an objective reliability index, the value of the partial safety factor to be applied to a determined variable as a function of its coefficient of variation. Figure 8 presents for the first and second limit states the curves corresponding to the variables soil Young's modulus and soil density for an objective reliability index $\beta=3$. Finally, Table 3 summarizes the values adopted for the partial safety factor assigned to each variable for the same objective reliability index.

Table 1. Correlation matrix considered in the analysis of examples and parametric studies

\begin{tabular}{|c|c|c|c|c|c|c|c|c|c|c|c|c|c|c|c|}
\hline & $E_{\mathrm{t}}$ & $\gamma_{i}$ & $\varphi_{\mathrm{t}}$ & $C_{\mathrm{t}}$ & $H$ & $\gamma_{t}$ & $u_{0}$ & $F_{\mathrm{c}}$ & $t$ & $R$ & $\omega_{\mathbf{s}}$ & $\omega_{\mathrm{c}}$ & $L_{b}$ & $D_{b}$ & $\Phi_{\mathrm{b}}$ \\
\hline$E_{\mathrm{t}}$ & 1 & & & & & & & & & & & & & & \\
\hline$\gamma_{t}$ & 0 & 1 & & & & & & & & & & & & & \\
\hline$\varphi_{\mathrm{t}}$ & 0 & 0 & 1 & & & & & & & & & & & & \\
\hline$c_{t}$ & 0.3 & 0 & 0 & 1 & & & & & & & & & & & \\
\hline$H$ & 0.7 & 0 & 0.3 & 0.3 & 1 & & & & & & & & & & \\
\hline$\gamma_{t}$ & 0.7 & 0 & 0 & 0.3 & 0.5 & 1 & & & & & & & & & \\
\hline$U_{\mathrm{c}}$ & -0.3 & 0 & 0 & 0.3 & 0 & 0 & 1 & & & & & & & & \\
\hline$F_{\mathrm{c}}$ & 0 & 0 & 0 & 0 & 0 & 0 & 0.2 & 1 & & & & & & & \\
\hline$t$ & 0 & 0 & 0 & 0 & 0 & 0 & 0 & -0.02 & 1 & & & & & & \\
\hline$R$ & 0 & 0 & 0 & 0 & 0 & 0 & 0 & 0 & 0 & 0.3 & 1 & & & & \\
\hline$\omega_{\mathrm{s}}$ & 0 & 0 & 0 & 0 & 0 & 0 & 0 & 0 & 0.3 & 0 & 1 & & & & \\
\hline$\omega_{\mathrm{c}}$ & 0 & 0 & 0 & 0 & 0 & 0 & 0 & 0 & 0 & 0.3 & 0 & 1 & & & \\
\hline$L_{t}$ & 0.2 & 0 & 0 & 0 & 0.2 & 0.2 & 0 & 0.2 & 0.2 & 0.2 & 0 & 0.3 & 1 & & \\
\hline$D_{\mathrm{t}}$ & 0.2 & 0 & 0 & 0 & 0.2 & 0.2 & 0 & 0.2 & 0.2 & 0.2 & 0 & 0.3 & 0 & 1 & \\
\hline$\Phi_{\mathrm{b}}$ & 0.2 & 0 & 0 & 0 & 0.2 & 0.2 & 0 & 0.2 & 0.2 & 0.2 & 0 & 0.3 & 0 & 0 & 1 \\
\hline
\end{tabular}


Table 2. Parametric studies: increment of $\beta$ measured for sample 1 when the variation coefficient for different variables changes from $10-80 \%$

\begin{tabular}{|c|c|c|c|c|c|c|}
\hline Variable & $\begin{array}{c}\stackrel{\text { Limit }}{\beta} \\
\text { V.C. }=10 \%\end{array}$ & $\begin{array}{c}\text { State } 1 \\
\quad \Delta \beta \\
\text { V.C. }=80 \%\end{array}$ & $\begin{array}{l}\stackrel{\text { Limit }}{\beta} \\
\text { V.C. }=10 \%\end{array}$ & $\begin{array}{c}\text { State } 2 \\
\Delta \beta \\
\text { V.C. }=80 \%\end{array}$ & $\begin{array}{l}\stackrel{\text { Limit }}{\beta} \\
\text { V.C. }=10 \%\end{array}$ & $\begin{array}{c}\text { State } 3 \\
\quad \Delta \beta \\
\text { V.c. }=80 \%\end{array}$ \\
\hline $\begin{array}{c}1: E_{\mathrm{t}} \\
3: \gamma_{\mathrm{t}} \\
4: H \\
5: C_{\mathrm{t}} \\
6: \varphi_{\mathrm{t}} \\
7: U_{0} \\
8: F_{\mathrm{c}} \\
9: t \\
10: R\end{array}$ & $\begin{array}{l}0.2684 E+01 \\
0.2406 E+01 \\
0.2435 E+01 \\
0.2438 E+01 \\
0.2990 E+01 \\
0.2839 E+01 \\
0.2441 E+01 \\
0.2465 E+01 \\
0.2406 E+01\end{array}$ & $\begin{array}{l}-0.1093 E+01 \\
-0.1522 E+01 \\
-0.1552 E+01 \\
-0.1400 E+01 \\
-0.3366 E+01 \\
-0.1028 E+01 \\
-0.7210 E+00 \\
-0.9570 E+00 \\
-0.1946 E+01\end{array}$ & $\begin{array}{l}0.4004 E+01 \\
0.3064 E+01 \\
0.3410 E+01 \\
0.3433 E+01 \\
0.3973 E+01 \\
0.3921 E+01 \\
0.3624 E+01 \\
0.4796 E+01 \\
0.3194 E+01\end{array}$ & $\begin{array}{l}-0.3556 E+01 \\
-0.2722 E+01 \\
-0.3050 E+01 \\
-0.9500 E-01 \\
-0.4076 E+01 \\
-0.1847 E+01 \\
-0.3455 E+01 \\
-0.4836 E+01 \\
-0.2452 E+01\end{array}$ & $\begin{array}{l}0.1380 E+02 \\
0.1083 E+02 \\
0.1197 E+02 \\
0.1205 E+02 \\
0.1378 E+02 \\
0.1348 E+02 \\
0.1265 E+02 \\
0.1630 E+02 \\
0.1055 E+02\end{array}$ & $\begin{array}{l}-0.1085 E+02 \\
-0.8956 E+01 \\
-0.1005 E+02 \\
-0.3200 E+00 \\
-0.1263 E+02 \\
-0.5439 E+01 \\
-0.1064 E+02 \\
-0.1482 E+02 \\
-0.9067 E+01\end{array}$ \\
\hline
\end{tabular}

SOIL YOUNG MODULUS beta $=3.0$

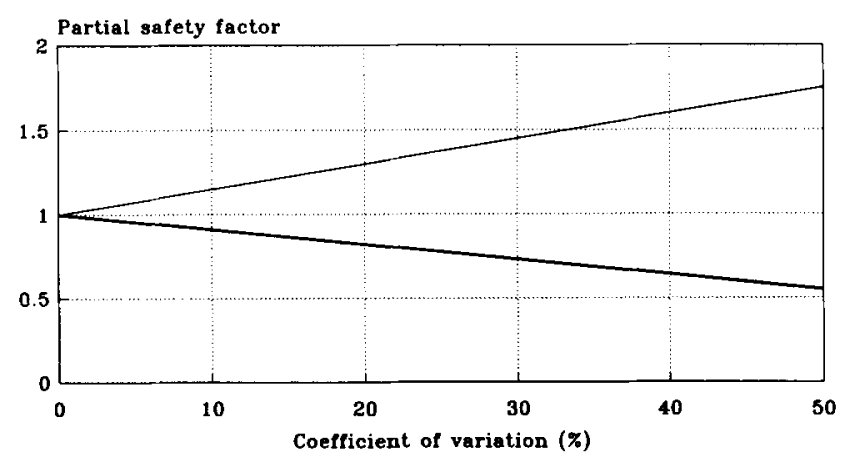

- goil fail alfa=.5 $\quad$ struct. fail alfa=.3

Figure 7. Design for ground elastic modulus. Upper line: Limit State 1. Lower line: Limit States 2 and 3. Abscisas: coefficient of variation of the variable $(\%)$. Ordinates: partial safety factor for $\beta=3.0$

\section{SOIL SPECIFIC WEIGHT beta $=3.0$}

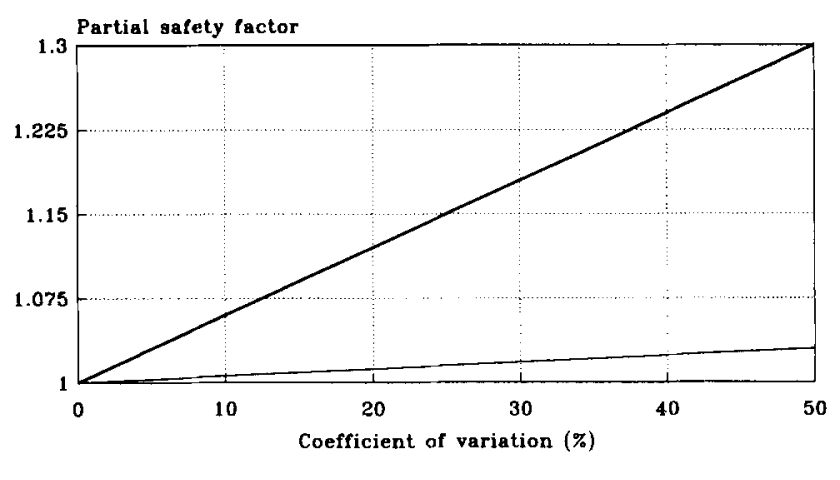

- soil fail alfa $=.02-$ struct. fail alfa $=.2$

Figure 8. Design curve for ground density. Upper line: Limit State 1. Lower line: Limit States 2 and 3. Abscisas: coefficient of variation of the variable (\%). Ordinates: partial safety factor for $\beta=3.0$

Table 3. Partial safety factors obtained for an objective $\beta=3$

\begin{tabular}{lccc}
\hline & & \multicolumn{2}{c}{$\begin{array}{c}\text { Partial safety factor } \\
\beta=3\end{array}$} \\
\cline { 4 - 4 } \multicolumn{1}{c}{$\begin{array}{c}\text { Nominal variation } \\
\text { Roefficient } \\
(\%)\end{array}$} & Limit State 1 & Limit States 2-3 \\
\hline Ground Young's modulus & 30 & 1.45 & 0.73 \\
Ground Poisson's modulus & 10 & 0.985 & 0.985 \\
Ground density & 5 & 1.003 & 1.03 \\
Excavation depth & 10 & 1.03 & 1.12 \\
Ground cohesion & 40 & 0.82 & 0.64 \\
Ground internal friction angle & 17 & 0.643 & 0.745 \\
Previous ground displacement & 40 & 1.48 & 0.64 \\
Shotcrete average resistance & 15 & 0.955 & 0.91 \\
Shotcrete layer thickness & 25 & 0.8875 & 0.6625 \\
Excavation radius & 5 & 0.9925 & 1.0225 \\
Geometric density: Steel reinforcement & 10 & 0.97 & 0.985 \\
Geometric density: Steel frames & 20 & 0.985 & 0.97 \\
Bolts length & 10 & 0.955 & 0.985 \\
Bolts geometric density & 30 & 0.9925 & 0.955 \\
Bolts diameter & 5 & & 0.9925 \\
\hline
\end{tabular}




\section{Conclusions}

The aim of this work was the introduction of classical structural reliability methods in the design of tunnel support structures. The characteristic curves or interaction diagram method was adopted for the mechanical approach to the problem, so that it was necessary to formulate the corresponding behavior laws for both the soil and the liner. A set of basic random variables was selected to describe the problem in terms of three basic limit states. The application of classical Level II reliability methods made feasible the evaluation of the corresponding reliability indexes. In this sense, the final basic technique adopted was a simplified procedure of the RMS type.

Of course, it must be assumed that those safety indexes can make no claim of representing an absolute measure of the real failure probability but, still, they do provide a means of comparing the reliability of different design situations. The proposed analytical model has been implemented in a computer program that has been used in the study of several practical cases. Some parametric studies have been conducted also. As a final result, following current tendencies, a practical proposal has been presented for the calibration of standard Level I partial safety factors.

\section{Acknowledgment}

An important part of the work described in this paper has been developed under contract with the Safety Department of the Spanish Institute of Geologic and Mining Technology (ITGME). The authors wish to express their gratitude for the support received from the engineers of that department, especially Mr. Gómez Heras and Mr. Ochoa. We should also like to recognize the impulse and criticism received from the engineers of the Spanish Ministry of Public Works (MOPTMA) at Asturias, Mr. García Arango and Mr. Hacar, who provided the data from the El Padrún tunnels.

\section{References}

1 Von Rabcewicz, L. The New Austrian Tunnelling Method. Water Power, 1964-65

2 Von Rabcewicz, L. Stability of tunnels under rock load. Water Power, 1969

3 Von Rabcewicz, L. Principles of dimensioning the supporting system for the New Austrian Tunnelling Method. Water Power, 1973

4 Gómez Lera, $M^{a}$. S. and Alarcón, E. Introduction to structural reliability and some of its applications (in Spanish). Instituto Eduardo Torroja Report, No. 408, Madrid, 1992

5 I.T.G.M.E.-SINEX, S.A. Establishment of safety levels in tunnels and galleries (in Spanish). Research project: Spanish Institute of Geologic and Mining Technology, Madrid, 1989-91

6 Laso, E. Application of Level II reliability methods to the design of tunnels liners (in Spanish). Ph.D. Thesis. Universidad Politécnica de Madrid, 1991
7 Sakurai, S. Approximate time-dependent analysis of tunnel support structure considering progress of tunnel face. Int. J. Numer. Analyt. Meth. Geomech. 1978

8 Sagaseta, C. Stresses and strains around excavations in elastoplastic continua (in Spanish). Ph.D. Thesis, Universidad Politécnica de Madrid, 1973

9 Fritz, P. An analytical solution for axisymmetric tunnel problems in elasto-viscoplastic media. Int. J. Numer. Analyt. Meth. Geomech. 1984, 8

10 Arango, I. G., Hacar, F., Hacar, M. A. and Alarcón, E. The function of the secondary lining in NATM. Rock Support in Mining and Underground Construction, ed. P. K. Kaiser et al., Balkema, 1992

11 I.T.G.M.E. Liners for underground openings (in Spanish). User Manual of program SOSTENIM devoted to the analysis of excavations by Characteristic Curves Method. Spanish Institute of Geologic and Mining Technology, Madrid, 1988

12 Hoek, E. and Brown, E. T. Underground excavations in rock. Institution of Mining and Metallurgy, London, 1980

13 Stille, H., Holmberg, M. and Nord, G. Support of weak rock with grounted bolts and shotcrete. Int. J. Rock Mech. Mining Sci. January, 1989

14 J.C.C.S. First order reliability concepts for design codes. C.E.B Bulletin No. 112, 1976

15 Cornell, C. A. A probability-based structural code. J. Am. Concrete Inst. 1969, 66(12)

16 Ditlevsen, O. Structural reliability and the invariance problem Solid Mechanics Report No. 22. University of Waterloo, Ontario, 1973

17 Hasofer, A. M. and Lind, N. C. Exact and invariant second moment code format. J. Eng. Mech. Div. ASCE 1979, 100

18 Melchers, R. E. Structural Reliability. Analysis and Prediction. Ellis Horwood, 1987, pp. 364-367

19 Ditlevsen, O. Principle of normal tail approximation. J. Eng. Mech. Div. ASCE 1981, 107

20 der Kiureghian, A. and Liu, P. L. Structural reliability under incomplete probability information. Report No. UCB/SESM85/01. Department of Civil Engineering, University of California at Berkeley, 1985

21 der Kiureghian, A. Measures of structural safety under imperfect states of knowledge. Report No. UCB/SESM-88/06. Department of Civil Engineering, University of California at Berkeley, 1988

22 Rosenblueth, E. Two points estimates in probabilities. Appl. Math. Modelling 1981, 5

23 Harr, M. E. Reliability Based Design in Civil Engineering McGraw-Hill, 1987

24 Casciati, F. and Faravelli, L. Fragility Analysis of Complex Structural Systems. John Wiley \& Sons, 1991, pp. 305-359

25 Liu, W. K. and Belitschko, T. (eds.) Computational Mechanics of Probabilistic and Reliability Analysis. Elme Press Int., 1989

26 Faravelli, L. Response surface approach for reliability analysis. $J$. Eng. Mech. ASCE 1989, 115

27 Schuëller, G. I. and Bucher, C. G. Computational stochastic structural analysis. A contribution to the software development for the reliability assessment of structures under dynamic loading. Prob. Eng. Mech. 1991, 6(2)

28 Cochran, W. G. and Cox, G. M. Experimental Designs. John Wiley \& Sons, 1957

29 Box, G. E. P. and Draper, N. R. Empirical Model Building and Response Surfaces. John Wiley \& Sons, 1987

30 Scheffé, H. The Analysis of Variance. John Wiley \& Sons, 1959

31 Peña, D. Statics. Models and Methods (in Spanish), Vol. 2. Ed. Alianza Universidad, 1987

32 C.E.B. Common Unified Rules for Different Types of Construction and Material. Bulletin d'Information No. 116-E. Comité Européen du Béton, Paris, 1976

33 Ravindra, M. K. and Galambos, T. V. Load and resistance factor design for steel. J. Struct. Div. ASCE 1978, 104

34 ITA W.G. on General Approaches to the Design of Tunnels. Guidelines for the design of tunnels. Tunnelling Ground Space Tech. 1988, 3(3)

35 Spanish Ministry for Public Works. El Padrún Tunnels. Oviedo-Campomanes Motorway (Asturias, Spain). Construction period 1989-1992. Technical Advisors: SINEX, S.A. 


\section{Appendix: Characteristic curves formulation}

\section{A.1 Soil elastoplastic characteristic curve formulation}

A.1.1 Soil plastic characteristics evaluation (valid for peak, residual, and nonassociative values)

$$
\begin{gathered}
m=\frac{1+\operatorname{sen} \varphi}{1-\operatorname{sen} \varphi} \\
\sigma_{\mathrm{d}}=\frac{2 c \cos \varphi}{1-\operatorname{sen} \varphi}
\end{gathered}
$$

A.1.2 Radial stress corresponding to plastification radius:

$$
\sigma_{\rho}=\frac{2 P_{0}-\sigma_{\mathrm{d}}^{\mathrm{P}}}{1+m^{\mathrm{P}}}
$$

where $P_{0}$ is the value of far field pressure.

\section{A.1.3 Plastification radius:}

$$
\rho=R\left[\left(\sigma_{\rho}+\frac{\sigma_{\mathrm{d}}^{\mathrm{R}}}{m^{\mathrm{P}}-1}\right) \frac{m^{\mathrm{R}}-1}{\sigma_{\mathrm{d}}^{\mathrm{R}}+P_{\mathrm{i}}\left(m^{\mathrm{R}}-1\right)}\right]^{1 / m^{\mathrm{R}}-1}
$$

$P_{\mathrm{i}}$ stands for the ground-structure interaction pressure.

A.1.4 For points within the elastic zone $(r \geq \rho)$ :

$$
u=\frac{P_{0}-\sigma_{\rho}}{2 G} \frac{\rho^{2}}{r} ; \quad G=\frac{E}{2(1+v)}
$$

A.1.5 For points within the plastic zone $(r<\rho)$ :

$$
\begin{aligned}
\sigma_{r}= & P_{0}-\left(P_{0}-\sigma_{\rho}\right)\left(\frac{\rho}{r}\right)^{2} \\
\sigma_{\theta}= & P_{0}+\left(P_{0}-\sigma_{\rho}\right)\left(\frac{\rho}{r}\right)^{2} \\
u_{1}= & \frac{1+v_{t}}{E_{t}}\left(R+1_{b}\right)\left[K_{2}\left(\frac{\varrho}{R+l_{b}}\right)^{m^{\mathrm{G}}+1}\right. \\
& \left.+K_{1}\left(\frac{\mathrm{Q}}{R+l_{b}}\right)^{1-m^{\mathrm{R}}}+K_{3}\right] \\
K_{1}= & \frac{\sigma_{d}^{\mathrm{R}}+\left(m^{\mathrm{R}}-1\right) \sigma_{\rho}}{m^{\mathrm{R}}-1}\left[\left(1-v_{t}\right) \frac{1+m^{\mathrm{R}} m^{\mathrm{G}}}{m^{r}+m^{\mathrm{G}}}-v_{t}\right] \\
K_{2}= & \left(1-v_{t}\right), \frac{m^{\mathrm{R}}+1}{m^{\mathrm{G}}+m^{\mathrm{R}}}\left[\sigma_{d}^{\mathrm{R}}+\left(m^{\mathrm{R}}-1\right) \sigma_{\rho}\right] \\
& +\left[2 P_{0}-\left(m^{\mathrm{R}}+1\right) \sigma_{\rho}-\sigma_{d}^{\mathrm{R}}\right] \frac{1}{m^{\mathrm{G}}+1} \\
K_{3}= & P_{0}-\sigma_{\rho}-K_{1}-K_{2} \\
\sigma_{r}= & \frac{\sigma_{d}^{\mathrm{R}}+P_{i}\left(m^{\mathrm{R}}-1\right)}{m^{\mathrm{R}}-1}\left[\frac{r}{R}\right]^{m^{\mathrm{R}}-1}-\frac{\sigma_{d}^{\mathrm{R}}}{m^{\mathrm{R}}-1} \\
\sigma_{\theta}= & m^{\mathrm{R}} \frac{\sigma_{d}^{\mathrm{R}}+P_{i}\left(m^{\mathrm{R}}-1\right)}{m^{\mathrm{R}}-1}\left[\frac{r}{R}\right]^{m^{\mathrm{R}}-1} \frac{\sigma_{d}^{\mathrm{R}}}{m_{\mathrm{R}}-1}
\end{aligned}
$$

Superscripts P, R, and G denote, respectively, peak, residual, and nonassociative values of plastic soil properties.

\section{A.2 Linear elastoplastic characteristic curve}

A.2.1 Concrete stress-strain relationship (Eurocode 2):

$$
\begin{aligned}
& \text { If } \varepsilon_{c} \leq 0.0020 \text { : } \\
& \sigma_{\mathrm{c}}=\frac{1}{1+\phi} \\
& \times \frac{1.1 \times 9.5\left[\frac{f_{\mathrm{c}}}{10}+8\right]^{1 / 3} \times 10^{4} \varepsilon_{\mathrm{c}}-f_{\mathrm{c}}\left(\frac{\varepsilon_{\mathrm{c}}}{0.002}\right)^{2} \mu_{1}}{1+1.1 \times 9.5\left[\frac{f_{\mathrm{c}}}{10}+8\right]^{1 / 3} \times 10^{4} \frac{\varepsilon_{\mathrm{c}}}{f_{\mathrm{c}} \mu_{1}}-2 \frac{\varepsilon_{\mathrm{c}}}{0.002}}
\end{aligned}
$$

If $0.0020 \leq \varepsilon_{\mathrm{c}} \leq 0.0035$ :

$$
\sigma_{\mathrm{c}}=f_{\mathrm{c}}
$$

where

$f_{\mathrm{c}}=$ mean value of concrete resistance

$\phi=$ concrete fluency coefficient

$\mu_{1}=$ concrete fatigue coefficient

\section{A.2.2 Steel stress-strain relationship:}

- For $-0.0035<\varepsilon_{\mathrm{S}}<-\varepsilon_{\mathrm{SY}}: \sigma_{\mathrm{S}}=\sigma_{\mathrm{SY}}$

- For $-\varepsilon_{\mathrm{SY}}<\varepsilon_{\mathrm{S}}<\varepsilon_{\mathrm{SY}}: \sigma_{\mathrm{S}}=\mathrm{E} \varepsilon_{\mathrm{SY}}$

- For $\varepsilon_{\mathrm{SY}}<\varepsilon_{\mathrm{S}}<0.01: \sigma_{\mathrm{S}}=\sigma_{\mathrm{SY}}$

where subindex $Y$ denotes yield stress and strain values of the steel considered either on frames or on concrete reinforcements and bolts.

A.2.3 All materials within elastic range $(0 \leq \varepsilon \leq 0.0012$, $n_{1}$ linearized segments):

$$
\begin{aligned}
& i=1, \quad u=\frac{P R^{2}}{E_{s}^{1} t} \\
& 1<i<n_{1}, \quad u=\frac{P R^{2}}{E_{s}^{i} t}-\frac{P^{i-1} R^{2}}{E_{s}^{i} t}+u^{i-1}
\end{aligned}
$$

where $\left(u^{i-1}, P^{i-1}\right)$ define the final point of segment $i-1$ and the equivalent value of the stiffness $E_{s}^{i}$ is obtained as:

$$
\begin{aligned}
& E_{\mathrm{s}}^{i}=E_{\mathrm{c}}^{i}+E_{\mathrm{s}}\left(W_{\mathrm{s}}+W_{\mathrm{C}}\right) \\
& E_{\mathrm{c}}^{i}=\frac{\sigma\left(\varepsilon^{i}\right)-\sigma\left(\varepsilon^{i-1}\right)}{0.0012}\left(n_{1}-1\right)
\end{aligned}
$$

the values $\sigma\left(\varepsilon^{i}\right)$ are computed by application of A.2.1. 
A.2.4 Plastified steel in frames $(0.0012<\varepsilon<0.0020$, $n_{2}$ linearized segments):

$$
\begin{aligned}
& i=n_{1}+1: u=\frac{P R^{2}}{E_{\mathrm{s}}^{n+1} t}+u^{n_{1}}-\frac{P^{n_{1}} R^{2}}{E_{\mathrm{s}}^{n_{1}} t} \\
& n_{1} \leq i \leq n_{1}+n_{2}: u=\frac{P R^{2}}{E_{\mathrm{s}}^{i} t}+u^{i-1}-\frac{P^{i-1} R^{2}}{E_{\mathrm{s}}^{i} t} \\
& \forall_{i}, n_{1}<i<n_{1}+n_{2}: E_{\mathrm{s}}^{i}=E_{\mathrm{c}}^{i}+E_{\mathrm{s}} w_{\mathrm{s}}
\end{aligned}
$$

A.2.5 Bolts contribution

Working traction load of the bolts:

$$
N_{\mathrm{b}}=\frac{\prod}{4} \phi_{b}^{2} E_{\mathrm{s}} \varepsilon_{\mathrm{b}}=\frac{\prod}{4} \Phi_{\mathrm{b}}^{2} \frac{\left(u-u_{1}\right)}{1_{b}} E_{\mathrm{s}}
$$

where $\left(u-u_{1}\right)$ stands for the relative radial displacement of both bolt heads. Then, for all the bolts in the section under consideration, $\varepsilon_{\mathrm{s}}^{y}$ represents the yield strain corresponding to the steel in bolts:

$$
\begin{aligned}
& P=d_{\mathrm{b}} \frac{\prod}{4} \phi_{b}^{2} \frac{\left(u-u_{1}\right)}{1_{\mathrm{b}}} E_{\mathrm{s}} ; \quad u \leq u_{\text {lim }} \\
& P=d_{\mathrm{b}} \frac{\prod}{4} \phi_{\mathrm{b}}^{2} \frac{u_{\mathrm{lim}}}{l_{\mathrm{b}}} E_{\mathrm{s}} ; \quad u>u_{\mathrm{lim}} \\
& u_{\mathrm{lim}}=l_{\mathrm{b}} \varepsilon_{\mathrm{s}}^{y}
\end{aligned}
$$

Conservatively, the radial displacement of that end of the bolt anchored to rock mass is computed following A.1:

- If $\left(R+l_{b}>\rho\right)$ :

$$
u_{1}=\frac{\left(1+v_{\mathrm{t}}\right)\left[P_{\mathrm{O}}\left(m^{\mathrm{P}}-1\right)-\sigma_{\mathrm{d}}^{\mathrm{P}}\right]}{E_{\mathrm{l}}\left(1+m^{\mathrm{P}}\right)} \frac{\mathrm{Q}^{2}}{\left[R+l_{\mathrm{b}}\right]}
$$

- If $\left(R+l_{\mathrm{b}}<\rho\right)$ :

$$
\begin{aligned}
u_{1}= & \frac{1+v_{\mathrm{t}}}{E_{\mathrm{t}}}\left(R+l_{\mathrm{b}}\right)\left[K_{2}\left[\frac{\vartheta}{R+l_{\mathrm{b}}}\right]^{m^{\mathrm{G}}+1}\right. \\
& \left.+K_{1}\left[\frac{\vartheta}{R+l_{\mathrm{b}}}\right]^{1-m^{\mathrm{R}}}+K_{3}\right]
\end{aligned}
$$

The resulting nonlinear $P-u$ relationship must be composed with those of A.2.3 and A.2.4 to finally obtain the general support structure characteristic curve formulation. 